\title{
AVALIAÇÃO DA APLICABILIDADE DE UM MODELO DE CREDIT SCORING COM VARIÁVEIS SISTÊMICAS E NÃO-SISTÊMICAS EM CARTEIRAS DE CRÉDITO BANCÁRIO ROTATIVO DE PESSOAS FÍSICAS
}

\section{AN EVALUATION ON THE APPLICABILITY OF A CREDIT SCORING MODEL, WITH SYSTEMIC AND NON-SYSTEMIC VARIABLES IN REVOLVING BANK CREDIT PORTFOLIO FOR INDIVIDUALS}

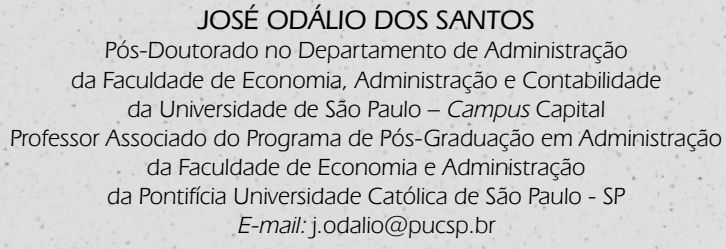

JOSÉ ODÁLIO DOS SANTOS

Pós-Doutorado no Departamento de Administração

da Faculdade de Economia, Administração e Contabilidàde da Universidade de São Paulo - Campus Capital

Professor Associado do Programa de Pós-Graduação em Administração da Faculdade de Economia e Administração

da Pontifícia Universidade Católica de São Paulo - SP E-mail:j.odalio@pucsp.br

\author{
RUBENS FAMÁ \\ Professor Doutor do Departamento de Administração \\ da Faculdade de Economia, Administração e Contabilidade \\ da Universidade de São Paulo - Campus Capital \\ Professor Titular do Programa de Pós-Graduação em \\ Ciências Contábeis e Atuariais \\ da Faculdade de Economia e Administração \\ da Pontifícia Universidade Católica de São Paulo - SP \\ E-mail: rfama@usp.br
}

\section{RESUMO}

As concessões de crédito rotativo às pessoas físicas (cheque especial e cartão de crédito) vêm crescendo significativamente nos últimos anos, o que, em parte, é explicado pela relativa estabilização da economia, maior geração de empregos e êxito no controle da inflação - fatores que interferem diretamente na capacidade de pagamento dos tomadores. Paralelamente, observa-se uma maior exposição histórica dos Bancos ao risco de inadimplência, ou seja, o do não-recebimento (parcial ou total) de créditos rotativos utilizados pelas pessoas físicas. Considerando o tamanho e a importância desse mercado aos grandes Bancos Comerciais e a economia como um todo, direciona-se essa pesquisa para: 1. detalhar os processos de análise subjetiva e objetiva de crédito realizada pelos principais Bancos privados nacionais; 2. abordar a função seletiva das taxas de juros em créditos rotativos; 3. destacar as principais características dos modelos de credit scoring e 4. propor um modelo de credit scoring para créditos rotativos composto por variáveis sistêmicas e não-sistêmicas, direcionado à redução do risco de inadimplência. A aplicabilidade do modelo proposto de credit scoring em uma amostra extraída da carteira de crédito de pessoas físicas de um importante Banco Comercial privado nacional de médio porte (Banco X - nome fictício), apresentou satisfatório índice de acerto na identificação de clientes prospectivos (96\%) e nãoprospectivos $(92 \%)$, levando à conclusão de que incluía e ponderava, adequadamente, as variáveis representativas da capacidade de pagamento dos tomadores.

Palavras-chave: Pessoas Físicas; Crédito; Risco; Retorno; Inadimplência.

\section{ABSTRACT}

The concessions of revolving credit to consumers (guaranteed check and credit card) have been growing significantly in the last few years, which is in part explained by the relative stabilization of the economy, higher levels of job creation and success in controlling inflation - factors that have a direct influence in the borrowers' payment capability. Likewise, a more significant historical exposition of the banks to insolvency risk is being observed, such as the risk of not getting paid (partially or totally) and the revolving credit borrowed by consumers. Considering the size and the importance of this market to the great commercial banks and to the economy as a whole, the scope of this research comprises the following points: 1. detailing the processes of subjective and objective credit analysis carried out by the main domestic private banks; 2. approaching the selective function of interest rates in revolving credits; 3 . highlighting the main characteristics of credit scoring models; and 4. proposing a model of credit scoring for revolving credits. This model is based on systemic and non-systemic variables and directed to the reduction of insolvency risk. The applicability of the credit scoring model proposed in a sample, extracted from the consumers credit portfolio which belongs to an important medium size Brazilian private commercial bank (Bank X - fictitious name), presented a satisfactory accuracy level in the identification of prospective (96\%) and non-prospective (92\%) clients, which led to the conclusion that it included and considered adequately the representative variables of borrowers' payment capability.

Keywords: Consumers; Credit; Risk; Return; Insolvency. 


\section{INTRODUÇÃO}

\subsection{Breve Relato do Desempenho do Mercado de Créditos Rotativos para Pessoas Físicas no Brasil}

Após a implantação do Plano Real, em junho de 1994, o setor financeiro teve de se ajustar a uma nova realidade econômica. A significativa queda inflacionária influenciou na necessidade de que os Bancos viessem a reaplicar seus ativos para investimentos alternativos geradores de receitas operacionais, haja vista a redução da receita com investimentos de curto prazo, criados para eliminar ou reduzir as perdas causadas pela inflação. A conseqüência imediata foi o aumento da concessão de empréstimos para todos os segmentos da economia - principalmente para o amplo mercado de pessoas físicas que vem se destacando pela geração de taxas de retorno atrativas - trata-se do spread calculado pela diferença entre as taxas de aplicação e captação nos mercados financeiros e de crédito.

Para o período de 2000 a 2005, o spread bruto médio anual obtido pelos Bancos Comerciais na principal modalidade de crédito rotativo (cheque especial) foi de 135,17\%. Trata-se de taxa de retorno expressiva que justifica a atratividade do segmento de pessoas físicas para a geração da receita operacional bancária. Jacobson e Roszbach (2003:615-633), também, destacam a importância do crédito à pessoa física e à geração de negócios das instituições financeiras.

O lado negativo dessa tendência foi que, paralelamente ao aumento da concessão de créditos rotativos para pessoas físicas (cheque especial e cartão de crédito), os Bancos passaram a assumir uma exposição proporcionalmente maior ao risco de inadimplência, ou seja, o do não recebimento (parcial ou total) dos juros e prestações do crédito.

Os Quadros 10 e 20 apresentam dados comparativos dos anos de 2000 e 2005 que evidenciam a maior concessão de créditos rotativos às pessoas físicas e maior exposição proporcional do risco de inadimplência assumida pelos bancos.
Nota-se um crescimento percentualmente muito maior das concessões de cartões de crédito do que as de cheque especial no período da comparação. Isso, assim pode ser explicado: primeiramente, os Bancos concederam limites de cheque especial às pessoas físicas, após detalhada análise de capacidade financeira e idoneidade. Posteriormente, ou nos anos mais recentes, começaram a conceder limites de cartão de crédito, igual ao concedido para as utilizações de cheque especial, visando aumentar ainda mais a receita de intermediação financeira. Essas duas modalidades de crédito representam recursos financeiros colocados à disposição das pessoas físicas para financiamento de gastos com os seus descasamentos de renda, sendo amortizadas via pagamento de juros mensais e prestações, calculados a partir do valor de utilização dos limites previamente aprovados pelos Bancos - por isso, são chamados de "rotativos".

\subsection{Justificativa para o Desenvolvimento da Pesquisa}

Ao destacar: 1) o expressivo crescimento e importância do mercado de créditos rotativos para pessoas físicas no Brasil e 2) a escassez de pesquisas acadêmicas no mercado nacional direcionadas à gestão do risco de créditos rotativos concedidos às pessoas físicas, considera-se oportuna a ocasião para o desenvolvimento deste artigo.

\subsection{Objetivos da Pesquisa}

Os objetivos principais da pesquisa são: 1) propor a utilização de um modelo de credit scoring para créditos rotativos composto por variáveis sistêmicas e não-sistêmicas diretamente relacionadas à capacidade de pagamento de pessoas físicas com renda assalariada e 2) verificar se a utilização do modelo em uma amostra de 2.000 clientes pessoas físicas extraída da carteira de crédito do Banco $X$ (nome fictício), contribuiria para a redução do atual risco de inadimplência em créditos rotativos. A não identificação do Banco do qual foram obtidas as informa-

\begin{tabular}{|l|c|c|c|}
\hline \multicolumn{1}{|c|}{ Itens/Período } & $\mathbf{2 0 0 0}$ & $\mathbf{2 0 0 5}$ & Variação $\mathbf{2 0 0 5 / 2 0 0 0}$ \\
\hline Cheque Especial (R\$ Bilhões) & 122 & 201 & $64,75 \%$ \\
\hline Taxa de Inadimplência Média (\%) & 3,3 & 5,7 & $72,73 \%$ \\
\hline
\end{tabular}

Fonte: Febraban, 02/2006

Quadro 1 - Concessões Anuais de Cheque Especial para Pessoas Físicas

\begin{tabular}{|l|c|c|c|}
\hline Itens/Período & $\mathbf{2 0 0 0}$ & $\mathbf{2 0 0 5}$ & Variação $\mathbf{2 0 0 5 / 2 0 0 0}$ \\
\hline Cartões de Crédito (R\$ Bilhões) & 10 & 67 & $570,00 \%$ \\
\hline Taxa de Inadimplência Média (\%) & 2,8 & 20,0 & $614,29 \%$ \\
\hline
\end{tabular}

Fonte: Febraban, 02/2006

Quadro 2 Concessões Anuais de Cartões de Crédito para Pessoas Físicas 
ções para a realização da pesquisa, foi a condição imposta pela área de gestão do risco de crédito. Essa postura foi justificada por considerar 0 acesso a dados confidenciais dos clientes - principalmente os de idoneidade e de relacionamento. Segundo o Banco, parte significativa dos clientes da carteira de crédito não gostaria de saber que agentes externos tiveram acesso aos seus dados (cadastrais, patrimoniais, financeiros e de idoneidade) e, com isso, poderia reduzir o volume de negócios, ou até mesmo encerrar o relacionamento.

\subsection{Metodologia}

- Revisão bibliográfica abordando as análises de crédito subjetiva e objetiva;

- Elaboração do modelo de credit scoring com o detaIhamento conceitual das variáveis sistêmicas e nãosistêmicas que compõem o modelo;

- Análise de viabilidade de utilização do modelo pelo Banco $X$, após a testagem em uma amostra de 2.000 clientes pessoas físicas do Banco $X$, que se apresentavam ativos, ou seja, utilizando créditos rotativos.

\section{CRÉDITO: CONCEITO, IMPORTÂNCIA E RISCO}

O crédito representa uma importante fonte de financiamento às pessoas físicas, principalmente em situações de descasamento dos prazos de recebimento da renda e pagamento das despesas. Segundo Brigham, Gapenski e Ehrhardt (2001:794) e Beckman (1949:145) a oferta de crédito por parte de empresas e instituições financeiras é um importante impulsionador da atividade econômica, por disponibilizar recursos financeiros às pessoas físicas para que possam financiar suas necessidades permanentes $e$ eventuais.

Dentre as várias conceituações, uma linha de raciocínio tem predominado entre os autores: crédito refere-se à troca de um valor presente por uma promessa de reembolso futuro, não necessariamente certa, em virtude do "fator risco" (SANTOS:2003:15).

Para Caouette, Altman e Narayanan (1999:1), o risco de crédito é um dos itens mais antigos da história do mercado financeiro, sendo assim definido: se o crédito constitui-se na expectativa de entrada de uma determinada quantia no caixa dos credores, em data futura, então o risco de crédito é a chance de que essa expectativa não se cumpra.

Para minimizar esse risco, destaca-se cada vez mais a importância da gestão do risco de crédito, baseada em procedimentos subjetivos (análise caso a caso) e objetivos (análise estatística), como instrumento para a adequada seleção, análise, precificação e, principalmente, monitoramento do risco de inadimplência, quando da ocorrência de fatores sistêmicos adversos. Gitman (2001:216) define riscos sistêmicos como os eventos externos desfavoráveis à geração de fluxos de caixa das empresas - analogamente de renda às pessoas físicas -, tais como: os aumentos das taxas de inflação, juros, câmbio, tributos, desemprego etc.

\section{TÉCNICAS DE ANÁLISE DE CRÉDITO}

Comumente, os profissionais da área de crédito das principais instituições financeiras utilizam dois procedimentos para analisar o risco de pessoas físicas em concessões de créditos rotativos (cheque especial e cartão de crédito): a "Análise Subjetiva" e a "Análise Objetiva". É fundamental a descrição de cada um deles, uma vez que determinam a qualidade do grau de exposição de risco de inadimplência em carteiras de crédito rotativo.

\subsection{Análise Subjetiva de Crédito Santos (2003:46) cita:}

A análise subjetiva, ou caso a caso, é baseada na experiência adquirida dos analistas de crédito, no conhecimento técnico, no bom-senso e na disponibilidade de informações (internas e externas) que lhes possibilitem diagnosticar se o cliente possui idoneidade e capacidade de gerar receita para honrar o pagamento das parcelas dos financiamentos.

Securato (2002:59) destaca que a análise subjetiva de crédito depende de um conjunto de informações contidas em um dossiê ou pasta de crédito. Dentre elas, cita as informações cadastrais, financeiras, patrimoniais, de idoneidade e de relacionamento. $A$ subjetividade é tratada nesse artigo como a capacidade, ou visão de cada analista de crédito, para identificar fatores de risco que comprometam a capacidade de pagamento de pessoas físicas em créditos rotativos.

\subsubsection{C's do Crédito Utilizados na Análise Subjetiva}

Segundo Gitman (1997:696), Ross, Westerfield e Jordan (1998:372):

Os analistas de crédito utilizam, freqüentemente, informações relacionadas ao caráter, capacidade, capital, colateral e condições como importantes condutores de valor para a decisão de concessão de crédito.

Essas cinco variáveis representam os "Cs" do crédito e são conceituados na Figura 10 .

Cada um dos C's tem sua importância para a melhor identificação do risco de crédito do cliente e, por isso, 


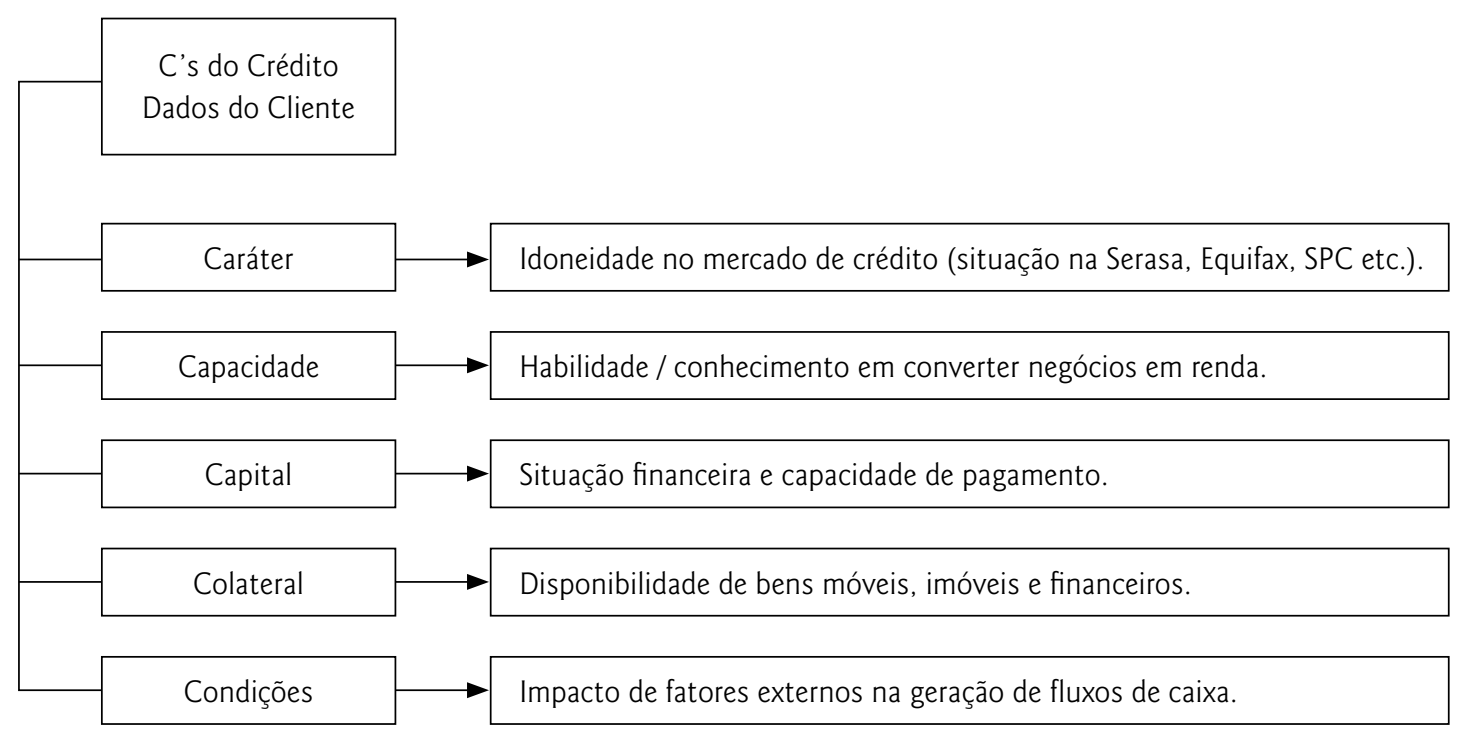

Fonte: Santos (2003:44)

Figura 1 C's de Crédito

são ponderados diferentemente nos modelos desenvolvidos para previsão de inadimplência, que são utilizados na "Análise Objetiva de Crédito".

\subsection{Análise Objetiva de Crédito}

A análise objetiva busca centrar-se nas metodologias estatísticas, com a finalidade de apurar resultados matemáticos que atestem a capacidade de pagamento dos tomadores.

Essa análise está amparada em pontuações estatísticas de riscos, conforme mencionado por Thomas (2000:150): "A pontuação de crédito é um instrumento estatístico desenvolvido para que o analista avalie a probabilidade de que determinado cliente venha a tornar-se inadimplente no futuro". Dentre as técnicas objetivas de gestão do risco de crédito, destacamos o credit scoring.

\subsubsection{Credit Scoring}

Trata-se de um modelo de avaliação do crédito baseado em uma fórmula estatística desenvolvida com base em dados cadastrais, financeiros, patrimoniais e de idoneidade dos clientes. Os dados dos clientes referem-se aos "Cs" do crédito abordados anteriormente. Fisher (1936) e Durand (1941) foram os precursores da metodologia do credit scoring para identificação de bons e maus tomadores de financiamento.

Para a composição dessa fórmula, os Bancos selecionam as principais informações cadastrais dos clientes e, em seguida, atribuem-lhes pesos ou ponderações de acordo com a importância destacada em suas políticas internas de crédito. Como resultado final, obterão um sistema de pontuação que possibilitará o cálculo de valores que serão interpretados em conformidade com a classificação de risco adotada. Essa classificação de risco dar-se-á por escalas numéricas, as quais recomendarão a aprovação ou a recusa dos financiamentos pleiteados pelas pessoas físicas.

Ao somar as pontuações de todos os clientes de uma carteira, define-se uma pontuação mínima, ou seja, o Ponto de Corte (ver Figura $2 \vartheta$ ), que servirá como base para a aprovação ou recusa do crédito. Como regra básica, pontuações de propostas de crédito acima do Ponto de Corte recomendam a aprovação do financiamento; propostas com pontuações abaixo do Ponto de Corte recomendam a recusa.

Identifica-se, também, o "Intervalo de Dúvida" ou de "Necessidade de Avaliação em Comitê", sempre que os clientes apresentarem pontuações muito próximas do Ponto de Corte, sejam elas inferiores ou superiores. Para isso, admite-se um intervalo estatístico de confiança a partir do Ponto de Corte, que melhor represente a política de exposição de risco de cada instituição financeira. Por exemplo, a decisão de análise em comitê poderia tanto considerar, para aprovação e recusa, clientes com pontuações inferiores a $5 \%$ do Ponto de Corte, como com pontuações superiores a $5 \%$ do Ponto de Corte. 


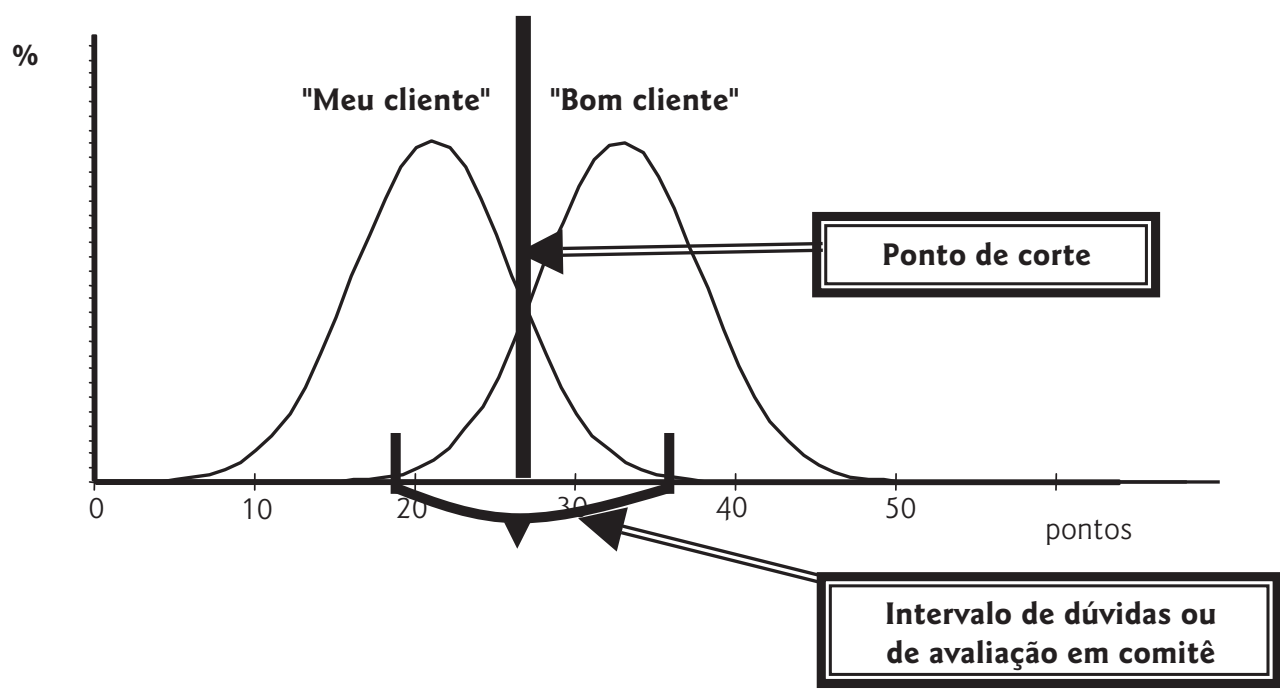

Fonte: Elaborada pelos autores

Figura 2 || Ponto de Corte e Intervalo de Dúvida - Credit Scoring

\section{A FUNÇÃO SELETIVA DAS TAXAS DE JUROS EM CRÉDITOS ROTATIVOS}

Quando da prospecção e análise de capacidade de pagamento de clientes pessoas físicas, os Bancos continuamente enfrentam o problema da "seleção adversa", ou seja, aprovação de créditos rotativos para tomadores de alto risco com elevada propensão à inadimplência. Isso, em parte, é influenciado pela manipulação e/ou omissão de informações, por parte das pessoas físicas, com o intuito de receberem aprovações dos Bancos para suas propostas de crédito (KORDICHEV, POWEL e TRIPÉ: 2005:4). A utilização de “informações imperfeitas” é muito comum e de difícil acesso aos profissionais bancários no momento da aprovação do crédito - é o caso, por exemplo, de informações que somente o cliente tem em tempo real, como a alteração de estado civil, doença de familiares, acidentes materiais repentinos, realização de investimento com prejuízo etc. $\mathrm{O}$ desconhecimento de informações que afetem negativamente a renda dos tomadores pode influenciar na aprovação de crédito com cobrança de taxas de juros que não reflitam a real situação financeira do cliente.

Stiglitz e Weiss (1981) destacam a contribuição que as taxas de juros podem exercer, como critério seletivo para a identificação da qualidade dos tomadores (bons ou maus riscos). Segundo os autores, tomadores dispostos a pagar altas taxas de juros podem evidenciar riscos elevados de crédito e possibilidades de futura redução da lucratividade bancária com a efetivação da inadimplência.

Conforme mostra a Figura $3 \mathbf{0}$, a partir do retorno ótimo $\left(\boldsymbol{R e}^{*}\right)$, a lucratividade bancária é reduzida em decorrência da concessão de crédito para tomadores inadimplentes. Com isso, acima da taxa $\mathbf{i}^{*}$, os Bancos enfrentam maiores probabilidades de perdas financeiras, uma vez que o retorno esperado sobre empréstimos concedidos para tomado-

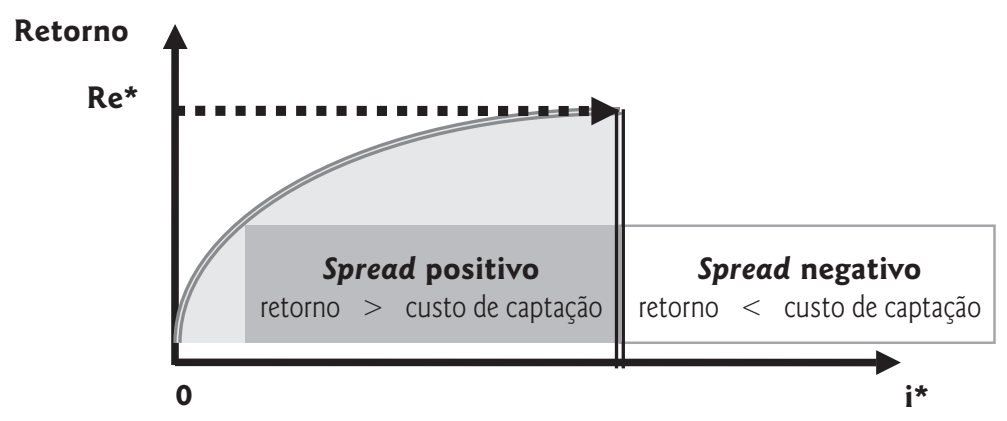

Taxa de juros

Fonte: Elaborada pelos autores

Figura 3 Comportamento do Resultado Bancário em Relação ao Custo de Captação 
res de alto risco é menor do que o retorno esperado sobre empréstimos concedidos para tomadores de baixo risco (taxas inferiores a $\mathbf{i}^{*}$ ).

Essa condição está presente nas carteiras de créditos rotativos, quando as elevadas taxas de juros são cobradas de clientes captados, via seleção adversa, e/ou que apre- sentaram perda (total ou parcial) de renda decorrente da ocorrência de fatores sistêmicos adversos, como a falência do empregador e o aumento das taxas de juros. Conseqüentemente, não conseguem pagar os juros em créditos rotativos, forçando os Bancos à renegociação com redução do spread e da lucratividade.

\section{APRESENTAÇÃO DO MODELO DE CREDIT SCORING PROPOSTO}

O modelo estatístico utilizado para dar suporte às tomadas de decisões sobre concessão de créditos rotativos às pessoas físicas foi desenvolvido a partir da extração de informações relacionadas a Aspectos Demográficos (AD), Idoneidade (I), Capacidade Financeira (CF), Colateral (C), Relacionamento Bancário (RB), Fonte Geradora de Renda (FGR) e Eventos Sistêmicos (ES).

A fórmula abaixo apresenta a relação entre a variável dependente $\mathbf{Y}$ (decisão de aprovação ou recusa dos créditos rotativos) e a conjugação das variáveis independentes citadas:

$$
\mathrm{Y}=\alpha+\mathrm{ADx}+\mathrm{Ix}+\mathrm{CFx}+\mathrm{Cx}+\mathrm{RBx}+\mathrm{FGRx}+\mathrm{ESx}+\varepsilon
$$

As variáveis $\alpha$ e $\varepsilon$ representam, respectivamente, o custo fixo para o Banco com os recursos (humanos e materiais) utilizados na análise de risco do crédito e a contribuição das informações cadastrais que não foram consideradas no modelo estatístico. A variável $\mathbf{x}$ representa a ponderação atribuída, ou grau de importância designado estatisticamente, a cada um dos itens componentes da fórmula.

A seguir, descreve-se cada uma das variáveis independentes que fazem parte da equação. É importante destacar que para cada variável independente, o Banco $X$ selecionou um conjunto de informações que, segundo os seus procedimentos de análise do risco de crédito, contribui para a identificação da capacidade de pagamento de seus clientes com renda assalariada, em créditos rotativos.

\subsection{Aspectos Demográficos}

As informações demográficas referem-se aos dados cadastrais dos tomadores extraídos das pastas de crédito do Banco X, conforme apresentado no Quadro $3 \mathbf{0}$.

\subsection{Idoneidade}

As informações de idoneidade (Quadro 4 () estão relacionadas ao comportamento de pagamento dos clientes no mercado de crédito e são monitoradas por dados restritivos como o número de protestos e número de cheques sem fundos devolvidos pelas agências credoras - esses dados são fornecidos por empresas de gerenciamento do risco de crédito, tais como a Serasa e a Equifax.

Internamente, os Bancos, também, podem monitorar a idoneidade através de seus relatórios gerenciais que apresentam informações do comportamento de pagamento de seus clientes, como os montantes movimentados em conta corrente e o índice de pontualidade no pagamento de juros e parcelas de créditos rotativos. Para Chakravarty e Scott (1998), quanto maior for o tempo ou a durabilidade da conta corrente, maiores serão as possibilidades dos Bancos em adquirir conhecimento sobre a idoneidade de seus clientes.

Essas mesmas informações restritivas são pesquisadas para avaliação da capacidade de pagamento e idoneidade da fonte geradora de renda assalariada dos tomadores - 0 pressuposto adotado na pesquisa é o de que quando a empresa empregadora começa a apresentar restrições de idoneidade acima da média aceitável para o setor, tende a

\begin{tabular}{|c|l|}
\hline Item & \multicolumn{1}{|c}{ Informações Demográficas } \\
\hline 1 & Idade \\
\hline 2 & Estado Civil \\
\hline 3 & Residência \\
\hline 4 & Tempo na Residência \\
\hline 5 & Número de Dependentes \\
\hline 6 & Plano de Saúde Familiar \\
\hline 7 & Plano de Seguro Residencial \\
\hline 8 & Plano de Seguro para Veículos \\
\hline 9 & Cargo na Atividade Assalariada \\
\hline 10 & Tempo de Atuação na Atividade Assalariada \\
\end{tabular}

Fonte: Elaborado pelos autores

Quadro 3 Informações Demográficas de Pessoas Físicas 


\begin{tabular}{|c|c|}
\hline Item & Informações de Idoneidade \\
\hline 1 & Caráter - Idoneidade do Cliente Pessoa Física \\
\hline 2 & Caráter - Idoneidade da Fonte Geradora de Renda Assalariada \\
\hline
\end{tabular}

Fonte: Elaborado pelos autores

Quadro 4 | Informações de Idoneidade

enfrentar maiores dificuldades de gerar fluxos de caixa para pagar o salário de seus funcionários. Conseqüentemente, aumenta o risco de inadimplência de clientes pessoas físicas em créditos rotativos.

\subsection{Capacidade Financeira}

As informações de capacidade financeira (Quadro 5 ( ) estão relacionadas à renda mensal líquida das pessoas físicas na atividade assalariada e ao índice de comprometimento de renda com as dívidas tradicionais (ex.: saúde, alimentação, moradia, educação, transporte etc.). Black e Morgan (1998) argumentam que deve ser dada atenção especial à análise de capacidade financeira, uma vez que consideram existir uma relação direta entre a perda de renda e a taxa de inadimplência de pessoas físicas em empréstimos bancários. Embora o índice de comprometimento de renda, naturalmente, apresente variações entre as pessoas físicas, é prática ou conservadorismo das principais instituições financeiras privadas brasileiras, considerar que a predominância das pessoas físicas apresenta renda consumida em $75 \%$, na média, por dívidas tradicionais. Os 25\% restantes são utilizados para calcular o valor das parcelas máximas ou os juros de créditos rotativos, que cada cliente pode suportar, mensalmente.

A renda mensal líquida é extraída dos comprovantes de pagamento de salário emitidos pelas fontes empregadoras.

\subsection{Colateral}

As informações de colateral (Quadro 6 吕) estão relacionadas à disponibilidade que o cliente tenha de bens (móveis e imóveis) para vinculação em contratos de crédito. Hynes (1998) destaca a importância inibidora da vinculação de bens patrimoniais em contratos de emprés- timos, ao considerar que essa condição torna os tomadores mais propensos à amortização pontual dos empréstimos, para que possam reaver os bens exigidos pelo Banco como garantia. O pressuposto adotado na pesquisa é o de que quanto maior é a riqueza patrimonial do cliente, maiores são as possibilidades de que venha transformar esses bens em recursos financeiros para pagar as dívidas onerosas.

Os dados patrimoniais dos clientes são obtidos, preferencialmente, da declaração de imposto de renda e/ou de documentos registrados em cartório que atestem a posse da totalidade ou predominância de seus bens mais valiosos.

\subsection{Relacionamento Bancário}

As informações de relacionamento bancário abrangem o tempo de relacionamento que o cliente possui com a sua principal instituição financeira, o índice médio de comprometimento da renda assalariada com o pagamento de dívidas onerosas, o número de cartões de crédito e o montante em aplicações financeiras. As pesquisas de Kane e Malkiel (1965), Saunders, Allen e Udell (1991), Berger e Udell (1994), Berlin e Mester (1977) e de Cetorelli (1997) são interessantes referenciais que tratam da importância do relacionamento para o Banco, como recurso para gerar informações e cobranças de taxas de juros compatíveis com o risco de crédito.

O Quadro $7 \bullet$ apresenta as informações de relacionamento selecionadas.

Essas informações são obtidas em documentos gerenciais das Instituições Financeiras, tais como a Posição Consolidada de Crédito, que apresenta dados gerais de relacionamento como: idade do relacionamento, limites de cheque especial e cartão de crédito, empréstimos pontuais,

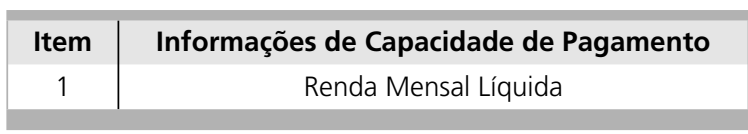

Fonte: Elaborado pelos autores

Quadro 5 | Informação de Capacidade de Pagamento

Fonte: Elaborado pelos autores

Quadro 6 Informação de Colateral 


\begin{tabular}{|c|l|}
\hline Item & \multicolumn{1}{|c|}{ Informações de Relacionamento Bancário } \\
\hline 1 & Tempo de Relacionamento com o principal Banco que tem negócios \\
\hline 2 & Patrimônio (Aplicações Financeiras) \\
\hline 3 & Número de Cartões de Crédito \\
\hline 4 & Índice Médio de Comprometimento de Renda com Dívidas Onerosas \\
\hline
\end{tabular}

Fonte: Elaborado pelos autores

Quadro 7 Relacionamento Bancário

valores de utilização das modalidades de financiamento, montante de aplicações financeiras, seguros etc.

\subsection{Fonte Geradora de Renda Assalariada}

As informações da fonte geradora de renda (Quadro $8 \mathbf{0}$ ) abrangem a identificação da empresa empregadora no que tange à sua natureza contratual, o tempo de existência no mercado, o grau de rotatividade ou realização de seus produtos/serviços em épocas de recessão ou de situações macroeconômicas desfavoráveis, o cargo exercido e o tempo de atuação na empresa. Segundo Santos (2003:55), quando pessoas físicas têm suas rendas extraídas de atividade empresarial, os Bancos devem coletar informações da fonte geradora de renda para confirmar a sua existência operacional, idoneidade e capacidade de pagamento dos salários futuros dos empregados.

Essas informações são extraídas de documentos que atestam a existência legal da empresa, como o Contrato Social registrado em cartório.

\subsection{Eventos Sistêmicos}

Os eventos sistêmicos (Quadro 9 O) compreendem a ocorrência de fatores externos, não controláveis, que afetem a renda e capacidade de pagamento das pessoas físicas e empresas. Wesley (1993) aborda o assunto ao destacar dois fatores determinantes do risco de inadimplência: a fraca qualidade no processo de análise de crédito (fator interno) e o agravamento da situação macroeconômica que pode resultar na escassez de tomadores saudáveis (fator externo). Segundo o autor, essa situação tende a influenciar a maior concentração de empréstimos com tomadores de "alto risco", o que pode resultar na diminuição da receita e da lucratividade bancária.

Especificamente para o foco desta pesquisa, destaca-se a situação macroeconômica e o comportamento das taxas de juros cobradas em créditos rotativos. O pressuposto é o de que uma situação macroeconômica desfavorável ocasiona uma redução do nível de atividade das empresas e, conseqüentemente, da taxa de emprego assalariado. O resultado esperado é que a conjugação desses dois eventos influenciará na redução da renda das pessoas físicas (total ou parcialmente) e no aumento da inadimplência bancária.

Após a seleção, conceituação e ponderação estatística de cada uma das variáveis independentes, foi construído o Modelo de Credit Scoring $\mathbf{C P}_{\mathbf{P F}}$ para identificação de clientes "prospectivos" (pontuais) e "não-prospectivos" (inadimplentes), a partir da confrontação das notas obtidas com o ponto de corte do modelo. Em seguida, procedeu-se à testagem do modelo para clientes pessoas físicas que apresentavam situação ativa em créditos rotativos, ou seja, estavam utilizando tanto o limite de cheque especial como o de cartão de crédito aprovados pelo Banco $X$.

O Quadro $10 \bullet$ apresenta as variáveis independentes do Modelo de Credit Scoring $\mathbf{C P}_{\mathbf{P F}}$, as Ponderações/

\begin{tabular}{|c|c|}
\hline Item & \multicolumn{1}{|c|}{ Informações da Fonte Geradora de Renda } \\
\hline 1 & Grau de Rotatividade dos Produtos/Serviços em Épocas de Recessão \\
\hline 2 & Tempo de Atividade Operacional da Fonte Empregadora \\
\hline 3 & Natureza Contratual (S.A., Ltda., S/C Ltda. etc.) \\
\hline
\end{tabular}

Fonte: Elaborado pelos autores

Quadro 8 Fonte Geradora de Renda

\begin{tabular}{|c|l|}
\hline Item & Eventos Sistêmicos - Perspectiva para os próximos $\mathbf{6}$ meses \\
\hline 1 & Situação Macroeconômica \\
\hline 2 & Comportamento da Taxa de Juros em Créditos Rotativos \\
\hline
\end{tabular}

Fonte: Elaborado pelos autores

Quadro 9 ! Eventos Sistêmicos 


\begin{tabular}{|c|c|c|}
\hline $\begin{array}{c}\text { Variáveis } \\
\text { Independentes do Modelo (X) }\end{array}$ & $\begin{array}{c}\text { Ponderação } \\
\text { Coeficientes } \\
\text { (1) }\end{array}$ & $\begin{array}{l}\text { Intervalo de Notas } \\
\text { Testado } \\
\text { (2) }\end{array}$ \\
\hline 1. Caráter / Idoneidade do Cliente PF & $8,10 \%$ & de 15 a 50 \\
\hline 2. Idade & $4,02 \%$ & de 10 a 40 \\
\hline 3. Estado Civil & $4,17 \%$ & de 15 a 25 \\
\hline 4. Residência & $4,06 \%$ & de 10 a 30 \\
\hline 5. Tempo de Moradia na Residência & $4,15 \%$ & de 10 a 35 \\
\hline 6. Estabilidade no Emprego Assalariado & $4,27 \%$ & de 5 a 50 \\
\hline 7. Cargo na Atividade Assalariada & $3,94 \%$ & de 10 a 30 \\
\hline 8. Renda Mensal Líquida & $5,38 \%$ & de 10 a 45 \\
\hline 9. Número de Dependentes & $4,86 \%$ & de -10 a 30 \\
\hline 10. Planos de Saúde Familiar & $3,97 \%$ & de 10 a 30 \\
\hline 11. Plano de Seguro Residencial & $2,48 \%$ & de 10 a 30 \\
\hline 12. Plano de Seguro para Veículos & $2,77 \%$ & de -10 a 30 \\
\hline 13. Número de Cartões de Crédito & $3,86 \%$ & de 5 a 30 \\
\hline 14. Tempo de Relacionamento com o principal Banco que tem negócios & $3,31 \%$ & de 10 a 40 \\
\hline 15. Patrimônio (Bens Móveis e Imóveis) & $3,89 \%$ & de 5 a 40 \\
\hline 16. Patrimônio (Aplicações Financeiras) & $4,13 \%$ & de 0 a 50 \\
\hline 17. Índice Médio de Comprometimento de Renda com Dívidas Onerosas & $5,84 \%$ & de -10 a 30 \\
\hline 18. Caráter / Idoneidade da Fonte Geradora de Renda Assalariada & $5,22 \%$ & de -10 a 25 \\
\hline 19. Grau de Rotatividade dos Produtos/Serviços da Empresa Empregadora & $4,61 \%$ & de -10 a 30 \\
\hline 20. Tempo de Atividade Operacional da Empresa Empregadora & $4,01 \%$ & de -10 a 20 \\
\hline 21. Natureza Contratual da Empresa Empregadora & $2,11 \%$ & de 0 a 25 \\
\hline 22. Situação Macroeconômica - Perspectiva para 6 meses & $5,45 \%$ & de -10 a 30 \\
\hline $\begin{array}{l}\text { 23. Comportamento das Taxas de Juros precificadas em Créditos Rotativos - } \\
\text { Perspectiva para os próximos } 6 \text { meses }\end{array}$ & 5,40 & de -10 a 30 \\
\hline
\end{tabular}

Fonte: Elaborado pelos autores

Quadro 10 Variáveis Independentes Ponderadas no Modelo de Credit Scoring $\mathbf{C P}_{\mathbf{P F}}$

Coeficientes Percentuais atribuídos estatisticamente e o Intervalo de Notas testado para cada uma das variáveis selecionadas.

\section{A PESOUISA}

\subsection{O Banco de Dados}

Para validação estatística do Modelo de Credit Scoring $\mathbf{C P}_{\mathbf{P F}}$, procedeu-se à aplicação da fórmula em uma amostra de 2.000 propostas de crédito rotativo de pessoas físicas com renda assalariada que apresentavam situação ativa no Banco X, ou seja, estavam utilizando seus limites de crédito. A renda variou, predominantemente, de $R \$ 500,00$ a $R \$ 2.500,00$ para pessoas físicas residentes e trabalhando na cidade de São Paulo.

Os 2.000 clientes ativos apresentavam situação de baixo e elevado risco em utilizações de créditos rotativos quando da testagem do modelo, sendo distribuídos em duas categorias: $\mathbf{1 . 0 0 0}$ “Clientes Prospectivos” com favorável histórico de crédito e índice de comprometimento da renda assalariada de até $30 \%$ com o pagamento de juros e parcelas em créditos rotativos; os restantes $\mathbf{1 . 0 0 0}$ foram classificados em “Clientes Não-Prospectivos” por apresentarem
A nota ponderada para cada cliente pessoa física foi obtida pela multiplicação da ponderação atribuída a cada variável (coluna 1) e sua respectiva nota (coluna 2). elevada utilização de créditos rotativos, índice de comprometimento da renda assalariada superior a 30\% com o pagamento de juros e parcelas em créditos rotativos e registro de informações restritivas no mercado (protestos e/ou cheques devolvidos). O objetivo foi o de verificar se o modelo identificaria as situações correntes de risco de cada cliente através de suas notas confrontadas com o ponto de corte.

$\mathrm{O}$ ponto de corte foi de 360 pontos, assumindo-se um intervalo de confiança de $5 \%$, ou seja, para pontuações entre 342 e 378 a decisão de crédito dar-se-ia mediante análise colegiada (em comitê).

Com o intuito de agregar ao modelo o risco de geração de fluxos de caixa da fonte empregadora em momentos macroeconômicos desfavoráveis, selecionaram-se pessoas físicas apresentando utilização de créditos rotativos no Banco X, com renda assalariada extraída de 80 empresas posicionadas em 16 setores: 


\begin{tabular}{|l|c|}
\hline \multicolumn{1}{|c|}{ Setores de Atividade } & Quantidade de Empresas Selecionadas \\
\hline Agricultura e Pecuária & 3 \\
\hline Alimentícios e Bebidas & 10 \\
\hline Comércio & 4 \\
\hline Construção & 8 \\
\hline Intermediação Financeira & 1 \\
\hline Máquinas e Equipamentos & 7 \\
\hline Produtos de Madeira & 1 \\
\hline Produtos de Metal & 15 \\
\hline Produtos Minerais Não Metálicos & 1 \\
\hline Produtos Químicos & 10 \\
\hline Saúde e Serviços Sociais & 1 \\
\hline Serviços para Empresas & 2 \\
\hline Têxteis & 6 \\
\hline Transporte Terrestre & 1 \\
\hline Varejo de Combustíveis & 2 \\
\hline Veículos Automotores & 8 \\
\hline Total & $\mathbf{8 0}$ \\
\hline
\end{tabular}

Fonte: Carteira de Crédito do Banco X

Quadro 11 Setor de Atividade e Quantidade de Empresas Selecionadas

Assim, pontuar-se-ia, mais adequadamente, o risco de inadimplência de cada pessoa física selecionada por considerar o grau de rotatividade dos produtos/serviços de sua fonte empregadora em épocas de crescimento, estabilidade e redução do nível da atividade econômica.

\subsection{Conceito atribuído à Inadimplência na Pesquisa}

A inadimplência foi medida pelo Número de Dias de Indisponibilidade de Saldo em Conta Corrente que os tomadores com informações restritivas de mercado (protestos e/ou cheques sem fundos) apresentavam para pagar os juros e parcelas dos créditos rotativos, a partir da data contratual. Sempre que essa situação acontece, é prática dos Bancos fazerem a cobertura do pagamento e, em seguida, entrarem em contato com o cliente, solicitando que regularizem a situação até uma data de tolerância.

\subsection{Periodos para Análise dos Resultados}

Os períodos foram separados em inicial $\left(\mathbf{t}_{\mathbf{0}}\right)$, representando o momento da aprovação dos limites de crédito rotativo para os 2.000 clientes da amostra e $\mathbf{t}_{+1}$, considerando 1. a situação efetiva/corrente de risco que os clientes apresentavam em créditos rotativos e $\mathbf{2}$. a situação de risco que os clientes apresentariam, caso o Banco $X$ utilizasse o Modelo de Credit Scoring $\mathbf{C P}_{\mathbf{P F}}$ em seus procedimentos de análise de risco.

Como no momento $\mathbf{t}_{\mathbf{0}}$ foi aprovado crédito rotativo aos 2.000 clientes, ou seja, para $100 \%$ da amostra, assumiu-se que a avaliação qualitativa efetuada pelos profissionais do Banco X considerou que a totalidade dos clientes se classificava na categoria de "Prospectivos". O modelo de credit scoring utilizado pelo Banco $X$, em $\mathbf{t}_{\mathbf{0}}$, incluía um conjunto de apenas 10 variáveis de natureza demográfica, financeira, patrimonial e de idoneidade dos clientes. Não considerava o impacto de fatores sistêmicos na renda e capacidade de pagamento dos tomadores, como o agravamento da situação contábil-financeira da fonte geradora de renda, que pode resultar em insolvência, ou falência, e a inevitável perda de emprego dos clientes pessoas físicas. O Banco $X$ não autorizou a divulgação da identidade dessas variáveis, nem dos nomes dos clientes e das empresas empregadoras que fazem parte de sua carteira de crédito.

O Quadro $12 \oslash$ apresenta um resumo da exposição de risco em créditos rotativos dos tomadores em $\mathbf{t}_{\mathbf{0}}$.

$\grave{A}$ medida que o relacionamento foi se estendendo, 50\% dos clientes selecionados (1.000) passou a apresentar perda (total ou parcial) de renda e/ou foi afetado por eventos desfavoráveis inesperados, como doença na família, separação conjugal, perdas materiais etc. Com isso, passou a não pagar pontualmente os juros e parcelas dos créditos rotativos, recebendo registros negativos em entidades de gestão do risco de crédito (Serasa e Equifax). Nessa condição, o Banco $X$ reverteu a classificação de risco desses clientes para "Não-Prospectivos", em $\mathbf{t}_{+1}$.

Em $\mathbf{t}_{+1}$, essa era a distribuição efetiva de risco em créditos rotativos do Banco X. (Ver Quadro 13 ).

\subsection{Resultados Obtidos com a Utilização do Modelo de Credit Scoring $\mathrm{CP}_{\mathrm{PF}}$ em $\mathrm{t}_{+1}$}

Visando verificar se a utilização do Modelo de Credit Scoring $\mathbf{C P}_{\mathbf{P F}}$ alteraria a exposição de risco em créditos rotativos do Banco $X$, em $\mathbf{t}_{+1}$, fez-se uma reavaliação da amostra de clientes problemáticos (1.000), através da 


\begin{tabular}{|l|c|c|}
\hline \multirow{2}{*}{ Decisão } & \multicolumn{2}{|c|}{ Clientes Prospectivos } \\
\cline { 2 - 3 } & Aprovação & Recusa \\
\hline Índice de Aprovação / Recusa & $100 \%$ & $0 \%$ \\
\hline
\end{tabular}

Fonte: Banco X

Quadro 12 Índice de Exposição de Risco em Créditos Rotativos em to

\begin{tabular}{|l|c|c|}
\hline \multicolumn{1}{|c|}{ Classificação de Risco } & Prospectivos & Não-Prospectivos \\
\hline $\mathbf{N}^{\circ}$ de Clientes & 1.000 & 1.000 \\
\hline Índice de Aprovação em $\mathbf{t}_{0}$ & $100 \%$ & $100 \%$ \\
\hline Comportamento de Pagamento & Pontual & Em Atraso \\
\hline
\end{tabular}

Fonte: Banco X

Quadro 13 | Índice de Exposição de Risco em Créditos Rotativos em $t_{+1}$

pontuação ou atribuição de escores numéricos. Em seguida, as notas foram confrontadas com o Ponto de Corte do modelo (360 pontos) para classificação nas categorias de "Prospectivo" e "Não-Prospectivo". Assumiu-se um intervalo de confiança de $5 \%$, ou seja, para pontuações entre 342 e 378 a decisão de crédito dar-se-ia mediante análise colegiada (em comitê).

Os resultados extraídos da amostra mostraram que a utilização do modelo sinalizaria mais eficientemente a elevada exposição de risco na carteira de créditos rotativos problemáticos, caso tivesse sido utilizado em $\mathbf{t}_{\mathbf{0}}$. Do total de 1.000 clientes na condição inicial de "Prospectivos" que reverteram a posição para "Não-Prospectivos", $89,20 \%$, ou 892 clientes, não teriam suas propostas de crédito aceitas - ou somente receberiam aprovação com a condicionante de que dessem bens de rápida liquidez (móveis, imóveis ou financeiros) em garantia; $4,80 \%$, ou 48 clientes, seriam encaminhados para análise colegiada (em comitê) e os restantes $6,00 \%$, ou 60 clientes, receberiam aprovação. Verifica-se, assim, que o modelo contribuiria com uma significativa redução de risco de $89,20 \%$, que poderia chegar a até $94,00 \%$, caso a análise colegiada, também, desse parecer desfavorável às propostas de crédito.

O Quadro 140 apresenta um resumo dos resultados.

Quando o Modelo de Credit Scoring $\mathbf{C P}_{\mathbf{P F}}$ (Quadro 15 D) é utilizado para a totalidade da amostra de 2.000 clientes, em $\mathbf{t}_{+1}$, se tem uma idéia melhor do grau de acerto ou eficiência.

Caso o Comitê desse parecer desfavorável às 48 propostas de crédito, o índice (Quadro 16 ) de acerto seria ainda maior.

\begin{tabular}{|l|c|c|c|}
\hline \multicolumn{1}{|c|}{ Classificação de Risco } & Aprovação & Análise em Comitê & Reprovação \\
\hline $\mathbf{N}^{\circ}$ de Clientes & 60 & 48 & 892 \\
\hline Índice & $6,00 \%$ & $4,80 \%$ & $89,20 \%$ \\
\hline Nota / Escore & Superior a 378 & Entre 342 e 378 & Inferior a 342 \\
\hline Comportamento de Pagamento & Em Atraso & Em Atraso & Em Atraso \\
\hline
\end{tabular}

Fonte: Banco X

Quadro 14 \Resultado da Utilização do Modelo de Credit Scoring $\mathbf{C P}_{\mathbf{P F}}$ em $\mathbf{t}_{+1}$

\begin{tabular}{|l|c|c|}
\hline \multicolumn{1}{|c|}{ Classificação de Risco } & Índice de Acerto (\%) & Índice de Erro (\%) \\
\hline Clientes Prospectivos & $100,00 \%$ & $0 \%$ \\
\hline Clientes Não-Prospectivos & $89,20 \%$ & $10,80 \%$ \\
\hline Média Aritmética & $94,60 \%$ & $5,40 \%$ \\
\hline
\end{tabular}

Fonte: Elaborado pelos autores

Quadro 15 Resumo dos Resultados do Modelo de Credit Scoring $\mathbf{C P}_{\mathbf{P F}}$ Modelo 


\begin{tabular}{|l|c|c|}
\hline \multicolumn{1}{|c|}{ Classificação de Risco } & Índice de Acerto (\%) & Índice de Erro (\%) \\
\hline Clientes Prospectivos & $100,00 \%$ & $0 \%$ \\
\hline Clientes Não-Prospectivos & $94,00 \%$ & $6,00 \%$ \\
\hline Média Aritmética & $97,00 \%$ & $3,00 \%$ \\
\hline
\end{tabular}

Fonte: Elaborado pelos autores

Quadro 16 Resumo dos Resultados do Modelo de Credit Scoring CP $_{\mathrm{PF}}$ Modelo

\section{CONSIDERAÇÕES FINAIS}

Os resultados mostraram que o Modelo capturaria meIhor a exposição corrente de risco do Banco X, por incluir um conjunto maior de variáveis representativas da real situação de risco dos clientes (total de 23 variáveis), e por ponderá-las de acordo com o seu justo ou aproximado grau de importância.

O modelo de credit scoring utilizado pelo Banco $X$, em $\mathbf{t}_{\mathbf{0}}$, incluía um conjunto de apenas 10 variáveis de natureza demográfica, financeira, patrimonial e de idoneidade dos clientes. Não considerava o impacto de fatores sistêmicos na renda e capacidade de pagamento dos tomadores - essa foi uma importante deficiência observada.

Ao incluir fatores sistêmicos no modelo proposto, através da situação da macroeconomia e grau de rotatividade dos produtos/serviços da fonte geradora de renda assalariada, foi feito um importante ajustamento no modelo, quer seja, o de considerar que, quando a situação da fonte empregadora é financeiramente ruim e as perspectivas da macroeconomia são desfavoráveis, maior passa a ser a probabilidade de inadimplência das pessoas físicas, em face das necessidades de corte de custos da empresa - o que inclui a demissão de funcionários. Como resultado, pessoas físicas desempregadas tendem a utilizar seus limites de crédito rotativo com maior freqüência e em valores cada vez maiores. Os elevados índices de utilização dos limites de cheque especial e cartão de crédito geram, em contrapartida, montantes de juros e parcelas a pagar abusivas, chegando ao ponto de os clientes não conseguirem mais realizar os pagamentos, seja temporária ou definitivamente.

Conforme se mostrou na Figura 3, acima da taxa i, os Bancos enfrentam maiores probabilidades de perdas financeiras, uma vez que o retorno esperado na concessão de créditos rotativos para clientes "Não-Prospectivos", ou de alto risco, é menor do que o retorno esperado sobre créditos rotativos para os clientes "Prospectivos" (taxas inferiores a i).

Considerando que o aumento sucessivo das perdas com a inadimplência contribui para a redução da lucratividade e rentabilidade dos Bancos, o resultado é o de também comprometer negativamente o retorno dos acionistas e dos demais supridores de capital. Para minimizar as possibilidades de ocorrência desse resultado e continuar obtendo êxito na meta principal da administração financeira, quer seja a da maximização da riqueza dos proprietários (Van Horne: 1995:2), é indispensável que os Bancos façam contínuas reavaliações de seus modelos de credit scoring, considerando não só a seleção e ponderação de variáveis internas (não-sistêmicas) como também a inclusão de eventos externos (sistêmicos) que apresentam relação direta com a renda e capacidade de pagamento dos tomadores. Nesse sentido, esse artigo traz uma importante contribuição às instituições financeiras e demais entidades de crédito que concedem financiamentos rotativos às pessoas físicas.

\section{Referências Bibliográficas}

BECKMAN, T. D.. Cases in credits and collections. New York: McGraw-Hill, 1949.

BERGER, A. N.; UDELL, G. F.. Lines of credit and relationship lending in small firm finance. The Wharton School, University of Pennsylvania - Financial Institutions Center. Working Paper 94-11, 1994, p. 1-7.

BERLIN, M.; MESTER, L. J.. Deposits and relationship lending. Federal Reserve Bank of Philadelphia. The Wharton School, University of Pennsylvania - Financial Institutions Center, Working Paper 96-18/R, 1997, p. 1-31.

BLACK, S. E.; MORGAN, D. P.. Risk and the democratization of credit card. Federal Reserve Bank of New York. Working Paper, 1998, p. 9-10. BRIGHAM, Eugene F.; GAPENSKI, Louis C.; EHRHARDT, Michael C.. Administração financeira - teoria e prática. São Paulo: Atlas, 2001. CETORELLI, N.. The role of credit market competition on lending strategies and on capital accumulation. Federal Reserve Bank of Chicago. Working Paper, December 1997, p. 1-33.

CHAKRAVARTY, S.; SCOTT, J. S.. Relationship and rationing in the consumer loan market. Purdue University. Working Paper, 1998, p. 1-13. CAUOETTE, John B.; ALTMAN, Edward I.; NARAYANAN, Paul. Gestão do risco de crédito - o próximo grande desafio financeiro. Rio de Janeiro: Qualitymark, 1999. 
DURAND, D.. Risk elements in consumer installment financing. National Bureau of Economic Research. New York, 1941.

FISHER, R. A.. The use of multiple measurements in taxonomic problems. Annals of Eugenics, 7, 1936, p. 179-188.

GITMAN, Lawrence J.. Princípios de administração financeira. $7^{\text {a }}$ ed. São Paulo: Harbra, 1997.

Princípios de administração financeira. $2^{\text {a }}$ ed. São Paulo: Bookman, 2001.

HYNES, R. M.. Three essays on consumer bankruptcy exemptions. PhD Thesis. University of Pennsylvania, USA, 1998, p. 1-21.

JACOBSON, T.; ROSZBACH, K.. Bank lending policy, credit scoring and value-at-risk. Journal of Banking \& Finance, 27, August 2003, pp. 615-633.

KANE, E. I.; MALKIEL, B. G.. Bank portfolio allocation, deposit variability, and the availability doctrine. Quarterly Journal of Economics, 79, February 1965, pp. 113-134.

KORDICHEV, A.; POWEL, J.; TRIPE, D.. Structural model of revolving consumer credit risk. Dep. of Finance Banking and Property, Massey University, Palmerston North, New Zealand, September, 2005, p. 1-13.

ROSS, Stephen A.; WESTERFIELD, Randolph W.; JORDAN, Bradford D.. Princípios de Administração Financeira. São Paulo: Atlas, 1998.

SANTOS, José Odálio dos. Análise de crédito - empresas e pessoas físicas. 2a ed. São Paulo: Atlas, 2003.

SECURATO, José R.. Crédito - análise e avaliação do Risco - pessoas físicas e jurídicas. São Paulo: Saint Paul Institute of Finance, 2002.

STIGLITZ, J. E.; WEISS, A.. Credit rationing in markets with imperfect information. The American Economic Review, 3, v. 71, June 1981, p. 393-409

THOMAS, Lyn C.. A survey of credit and behavioural scoring: forecasting financial risk of lending to consumers. International Journal of Forecasting, 16, 2000, p. 149-172.

WESLEY, D. H.. Credit risk management: lessons for success. The Journal of Commercial Lending, August 1993, p. 32-38.

\section{NOTA - Endereço dos autores}

Pontifícia Universidade Católica

Rua Monte Alegre, 984 - Perdizes

São Paulo - SP

05014-901
Universidade de São Paulo

Faculdade de Economia, Administração e Contabilidade Av. Prof. Luciano Gualberto, 908 - Cidade Universitária São Paulo - SP

05508-900 